\title{
Impacts of Modifiable Factors on Ambient Air Pollution: A Case Study of COVID-19 Shutdowns
}

\author{
Rebecca Tanzer-Gruener ${ }^{1}$, Jiayu $\mathrm{Li}^{1}$, S. Rose Eilenberg ${ }^{1}$, Allen L. Robinson ${ }^{1}$, Albert A. Presto ${ }^{1 *}$ \\ ${ }^{1}$ Department of Mechanical Engineering, Carnegie Mellon University, Pittsburgh, Pennsylvania, \\ 15213, United States \\ Corresponding Author \\ *(A.A.P) E-mail: apresto@ andrew.cmu.edu
}

\begin{abstract}
Modifiable sources of air pollution such as traffic, cooking, and electricity generation emissions can be modulated either by changing activity levels or source intensity. Although air pollution regulations typically target reducing emission factors rather than altering activity, the COVID-19 related closures offered a novel opportunity to observe and quantify the impact of activity levels of modifiable factors on ambient air pollution in real-time. We use data from a network of twenty-seven low-cost Real-time Affordable Multi-Pollutant (RAMP) sensor packages deployed throughout urban and suburban Pittsburgh along with data from EPA regulatory monitors. The RAMP locations were divided into four site groups based on land use (High Traffic, Urban Residential, Suburban Residential, and Industrial). Concentrations of $\mathrm{PM}_{2.5}, \mathrm{CO}$, and $\mathrm{NO}_{2}$ following the COVID-related closures at each site group were compared to measurements from "business as usual" periods in March 2019 and 2020. Overall, $\mathrm{PM}_{2.5}$ concentrations decreased across the domain by $3 \mu \mathrm{g} / \mathrm{m}^{3}$. Intra-day variabilities of the pollutants were computed to attribute pollutant enhancements to specific emission sources (i.e. traffic and industrial emissions). There was no significant change in the industrial related intra-day variability of $\mathrm{PM}_{2.5}$ at the Industrial sites following the COVID-related closures. The morning rush hour induced $\mathrm{CO}$ and $\mathrm{NO}_{2}$ concentrations at the High Traffic sites were reduced by $57 \%$ and $43 \%$, respectively, which is consistent with the observed reduction in commuter traffic $(\sim 50 \%)$. The morning rush hour $\mathrm{PM}_{2.5}$ enhancement from traffic emissions fell from $\sim 1.5 \mu \mathrm{g} / \mathrm{m}^{3}$ to $\sim 0 \mu \mathrm{g} / \mathrm{m}^{3}$ across all site groups. This translates to a reduction of $0.125 \mu \mathrm{g} / \mathrm{m}^{3}$ in the daily average $\mathrm{PM}_{2.5}$ concentration. If $\mathrm{PM}_{2.5}$ National Ambient Air Quality Standards (NAAQS) are tightened these calculations shed light on to what extent reductions in traffic related emissions are able to aid in meeting more stringent regulations.
\end{abstract}

\section{$\underline{\text { Introduction }}$}

Sources of ambient air pollution are generally associated with human activities such as traffic, cooking, and electricity generation. These sources are modifiable factors; emissions can be modulated either by changing activity levels or the source intensity (e.g., emission factor). Air pollution regulation has traditionally relied on reducing emission factors rather than curbing activity. Although previous studies have assessed impacts of event-related step changes in emission sources on air quality ${ }^{[1-4]}$, social distancing measures implemented in response to COVID-19 offer a natural experiment to observe and quantify the impacts of modifiable factors, specifically large shocks to activity, on ambient air pollution in real time with an unprecedented scope, speed, and duration. 
In March 2020, 48 U.S. states implemented precautions to limit transmission of COVID-19 ${ }^{[5]}$. In many cases, these measures represented a step-change in activity and accompanying pollutant emissions. This study focuses on data collected in Pittsburgh, PA, which is representative of the rapid changes in activity associated with social distancing measures. A timeline of the closures effecting PA and the upwind state of Ohio can be found in Table S1 in the Supplemental Information (SI) and show that activity was "business as usual" through March 13 ${ }^{[6-10]}$ and rapidly transitioned to lower activity, with the majority of schools and non-essential businesses closed or operating in reduced capacity by March 16.

The closing of schools and businesses has a clear impact on activity levels and therefore air pollutant emissions. In this paper, we use data from both a distributed network of low-cost air pollutant sensors and the Environmental Protection Agency (EPA) regulatory network to examine how changes in activity impacted ambient air pollution. We compare concentrations of fine particulate matter $\left(\mathrm{PM}_{2.5}\right), \mathrm{CO}$, and $\mathrm{NO}_{2}$ from the post-COVID shutdown period (March 1431, 2020) to business as usual periods in March 2019 and 2020.

\section{$\underline{\text { Methods }}$}

$\mathrm{CO}$ and $\mathrm{PM}_{2.5}$ were measured using a distributed network of low-cost sensors. The Real-time Affordable Multi-Pollutant (RAMP) sensor package has been deployed throughout the city of Pittsburgh and surrounding suburbs since 2016 ${ }^{[11]}$. The RAMPs use electrochemical sensors (AlphaSense LLC) to measure CO. $\mathrm{PM}_{2.5}$ is measured via light scattering using either MetOne Neighborhood Monitors or PurpleAir PA-IIs. Previous work details the calibration ${ }^{[12,13]}$ and deployment ${ }^{[14-16]}$ of these sensor packages.

In March 2020 there were twenty-seven active RAMP sites in the Pittsburgh region. Figure S2 in the SI shows the locations of the RAMPs. The RAMP sites were grouped into four categories: High Traffic $(n=3)$, Urban Residential $(n=11)$, Suburban Residential $(n=8)$, and Industrial ( $n$ $=4$ ). Site groupings were determined according to the same methodology as was used in previous work ${ }^{[14]}$ and are described in detail in the SI.

78
One concern with low-cost pollutant sensors is uncertainty in the measurements ${ }^{[17-21]}$. We have previously shown that the mean absolute error relative to a reference measurement in the hourly averaged $\mathrm{CO}$ measurements is $\pm 49 \mathrm{ppb}^{[11]}$. Uncertainty in $\mathrm{PM}_{2.5}$ is a strong function of averaging time; 1-hr data has a relatively large uncertainty $\left(\sim 4 \mu \mathrm{g} / \mathrm{m}^{3}\right)$ that falls to $\sim 1 \mu \mathrm{g} / \mathrm{m}^{3}$ after sufficient averaging time ${ }^{[12,19]}$. In this paper we group sites that have similar land uses in order to increase effective averaging time, thus reducing uncertainty to $1.1 \mu \mathrm{g} / \mathrm{m}^{3[19]}$.

To supplement the RAMP data, EPA Air Quality System (AQS) data collected by the Allegheny County Health Department (ACHD) was also analyzed. The ACHD network includes two sites with $\mathrm{NO}_{2}$ measurements. One is a High Traffic site, and the other is a Suburban Residential site; both are shown in Figure S2.

We have also quantified the reduction in traffic. We compared traffic camera data on a main commuter highway in March 2020 (post-closures) to historical vehicle counts on the same 
roadway during the same time of day (8am: morning rush hour). We estimate that commuter vehicle traffic was reduced by $48 \%$. This estimate is consistent with Google mobility data which estimates that in Allegheny County workplace related mobility decreased by $45 \%{ }^{[22]}$.

\section{Results and Discussion Concentration reductions due to activity changes}

In order to control for non-COVID related variables (i.e. weather) we compared post-COVID pollutant measurements in March 2020 to typical March pollutant measurements from March 2019. March 2019 was designated as the "pre-COVID period" for this analysis because of a high frequency of strong temperature inversions during the first two weeks of March 2020, as shown in Figure S6 in the SI. Across the entire RAMP network, pollutant concentrations fell 32\% following the COVID-related closures; $\mathrm{PM}_{2.5}$ concentrations decreased by $\sim 3 \mu \mathrm{g} / \mathrm{m}^{3}$, from 9.5 $\mu \mathrm{g} / \mathrm{m}^{3}$ (March 2019) to $6.4 \mu \mathrm{g} / \mathrm{m}^{3}$ (March 14-31, 2020).

112 2. There is a sharp rise in CO concentrations between an overnight stable period and the morning 113 rush hour (7-8am).

114
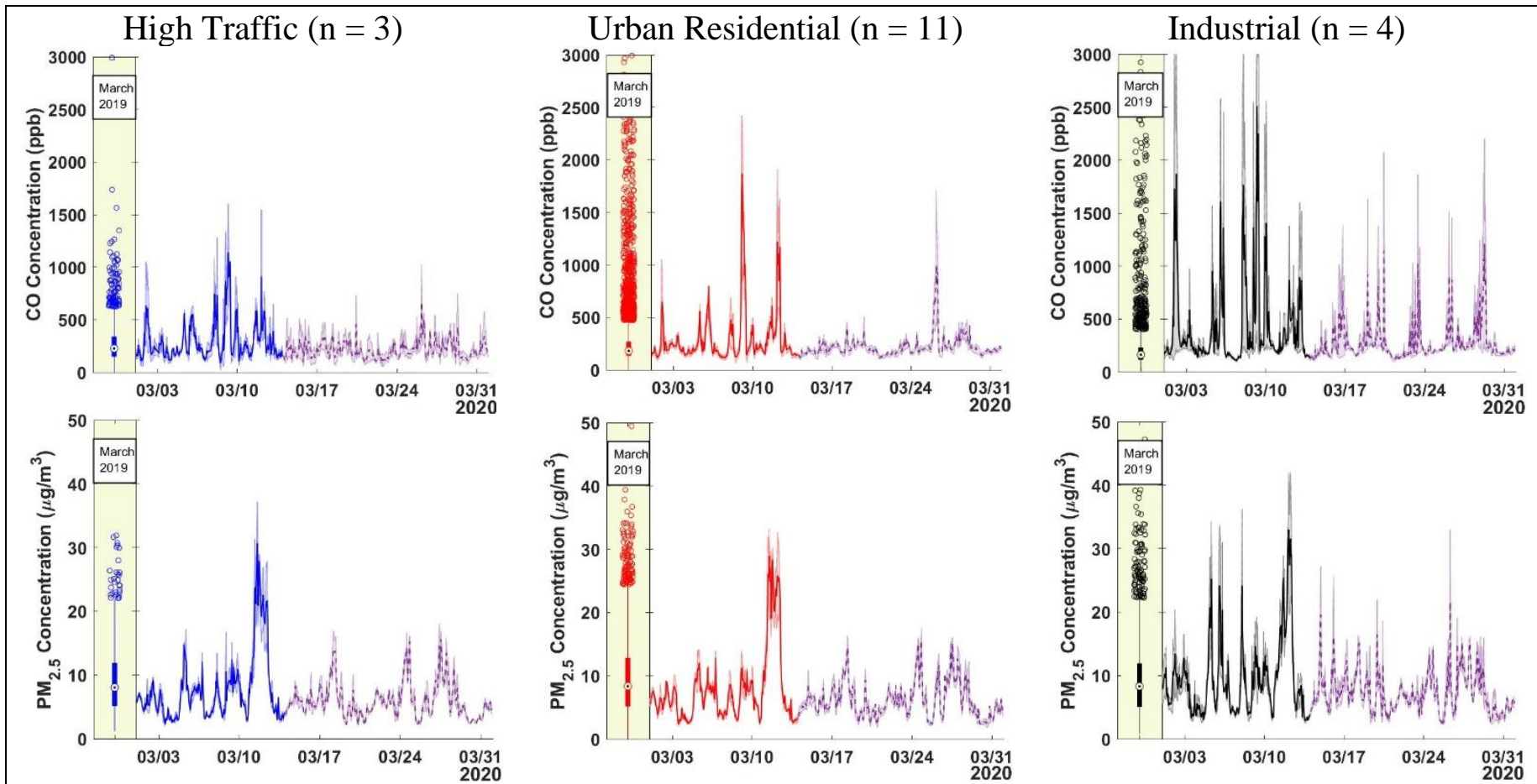

Figure 1. Hourly average concentrations of PM 2.5 and CO for three of the site groupings during March 2020. The High Traffic, Urban Residential, and Industrial sites are shown while the Suburban Residential sites are shown in Figure S3 in the SI. The solid (pre-COVID closures) and dashed (post-COVID) lines are the mean concentrations for all the sites in each group. The shaded area around each line represent the $25^{\text {th }}$ and $75^{\text {th }}$ percentiles of the data from the site groups. The boxplots show the corresponding March 2019 data for all sites in each site group. The center of the boxes (indicated by a dot) are the median, the 
top and bottom of each box represents the $25^{\text {th }}$ and $75^{\text {th }}$ percentiles of the data for all sites over the entire month in that site group. The whiskers of the boxes represent 2.7 standard deviations and the outliers represent the remaining data.

115

116

117

118

119

120

121

122

123

124

125

126

127

128

129

130

131

132

133

134

135

136

137

138

139

140

141

142

143

In addition to the daily traffic-driven pattern, the Industrial sites are also impacted by $\mathrm{CO}$ emissions from the nearby industrial sources. These emission events generate concurrent spikes of $\mathrm{CO}$ and $\mathrm{PM}_{2.5}$ that are evident in Figure 1.

The box plots on the left of each panel in Figure 1 show the distribution of $\mathrm{CO}$ and $\mathrm{PM}_{2.5}$ measurements from March 2019. Overall, CO concentrations in the pre-COVID period in March 2020 are within the instrument uncertainty of 2019 and are therefore indistinguishable from each other. Descriptive statistics comparing the two datasets are shown in table S4 in the SI. This suggests that the main emission sources - countywide traffic and industrial emissions - were similar between 2019 and 2020 before social distancing.

Compared to March 2019 and pre-closure 2020, CO concentrations are both lower and less variable in the post-COVID closure period in 2020. For March 14-31, 2020, the mean concentration at the High Traffic sites fell $19 \%$ and the $90^{\text {th }}$ percentile fell $22 \%$ when compared to the averages of March 2019 and pre-closures 2020. This is consistent with the large decrease in traffic volume and supported by the diurnal patterns in Figure 2. The morning rush hour peak is significantly smaller in the post-COVID period at the High Traffic sites and seems to have been eliminated completely at the Suburban Residential sites. $\mathrm{NO}_{2}$, which is also a marker for traffic emissions, shows a similar pattern as CO (Table 1 and S5 in the SI). Concentrations are lower and less variable in the post-COVID period when compared to the March $2019 \mathrm{NO}_{2}$ measurements.

Figure 1 and 2 show similar trends for $\mathrm{PM}_{2.5}$. Concentrations during the pre-COVID period in 2020 are similar to March 2019. Concentrations in the post-COVID period are lower and less variable. For example, Figure 2 shows that for the High Traffic sites the $\mathrm{PM}_{2.5}$ increase associated with the morning rush hour fell from $1.4 \mu \mathrm{g} / \mathrm{m}^{3}$ in 2019 to zero in the post-COVID period.
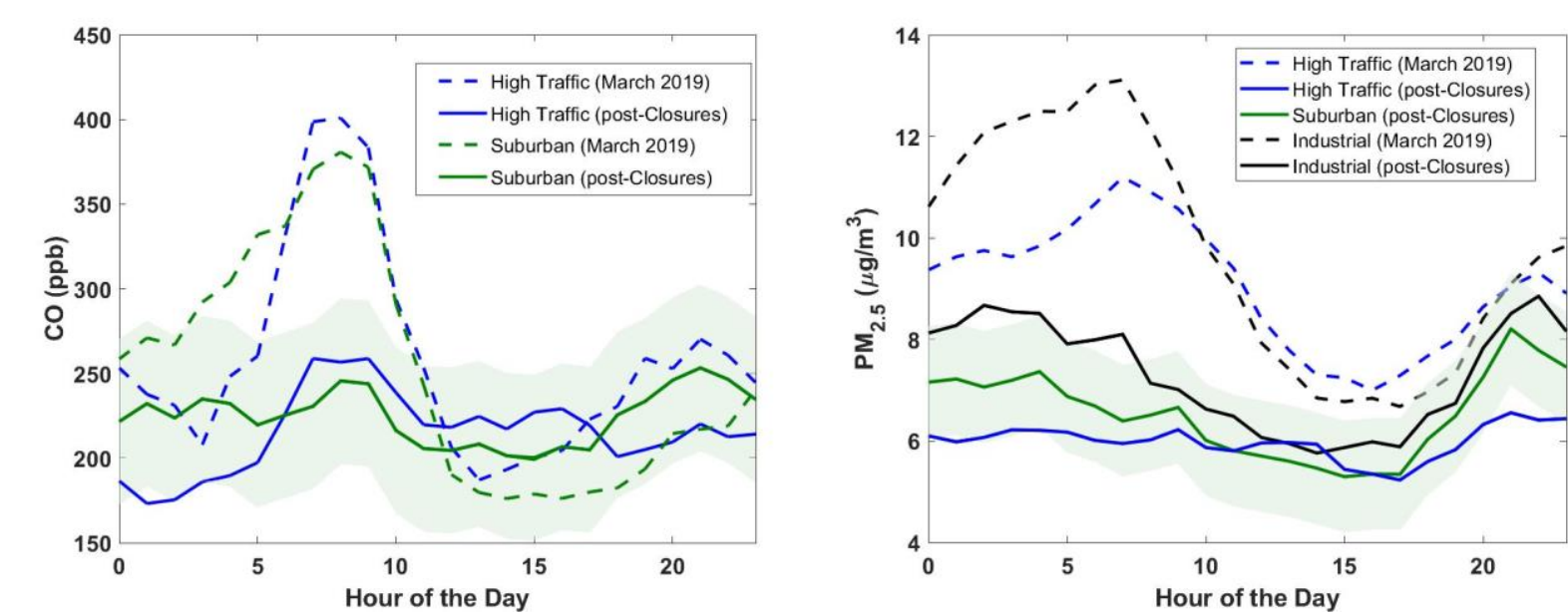

Figure 2. Average diurnal patterns for selected site groups for CO (left) and PM 2.5 (right). Dashed lines show the pre-closure diurnal patterns from March 2019 and the solid lines show the 2020 post-COVID period. The shaded 
area around the line for the Suburban post-closure diurnal indicates the instrument uncertainty for each instrument $\left(1.1 \mu \mathrm{g} / \mathrm{m}^{3}\right.$ and $49 \mathrm{ppb}$ for $P M_{2.5}$ and $\mathrm{CO}$, respectively).

Figure 2 shows that the majority of the $\mathrm{PM}_{2.5}$ enhancement at the industrially influenced sites occurs at night which is consistent with previous studies ${ }^{[14]}$. This is because of a combination of emissions and boundary layer height. During overnight hours, the boundary layer is low. Many other sources, such as traffic, have less activity during overnight hours, whereas the industrial sources operate 24 hours per day. Thus, there are local enhancements of $\mathrm{PM}_{2.5}$ overnight at the Industrial sites ${ }^{[23,24]}$. While average $\mathrm{PM}_{2.5}$ concentrations were lower at the Industrial sites in the post-COVID compared to pre-COVID periods (25\% reduction), these sites still had higher concentrations than all other site groups $\left(1.1 \mu \mathrm{g} / \mathrm{m}^{3}\right)$. This suggests that the industrial activity was maintained during the shutdown.

One challenge with attributing $\mathrm{PM}_{2.5}$ reductions to changes in human activity is that the majority Thus, while changes in $\mathrm{CO}$ are a good marker for changes in direct combustion emissions, any changes in measured $\mathrm{PM}_{2.5}$ concentrations may be driven by several other factors, including upwind emissions, boundary layer height, and weather. In the following section, we compare intra-day variations in enhancements that are associated with local emissions, and therefore should remove influences of these outside factors that may confound comparisons between the pre- and post-COVID periods.

\section{Changes in source-related intra-day variability of pollutant concentrations}

We defined two intra-day variations which focus on traffic and industrial-related enhancements. We first define the traffic-related enhancement as the difference between the morning rush hour peak (mean 7-8am) and the overnight stable period (mean 2-3am) for $\mathrm{PM}_{2.5}, \mathrm{CO}$, and $\mathrm{NO}_{2}$. Second, we define an industrial enhancement for the sites in the Industrial group as the overnight difference (mean 2-4am) between the four Industrial sites and the five Suburban Residential sites with the lowest concentrations as this is representative of the industrial emissions overnight at 


\begin{tabular}{|c|c|c|c|c|c|}
\hline & Site Group & $\begin{array}{l}\text { Pre- } \\
\text { COVID } \\
\text { Traffic } \\
\text { Related } \\
\text { Variability }\end{array}$ & $\begin{array}{l}\text { Post- } \\
\text { COVID } \\
\text { Traffic } \\
\text { Related } \\
\text { Variability }\end{array}$ & $\begin{array}{l}\text { Pre-COVID } \\
\text { Industrial } \\
\text { Related } \\
\text { Variability }\end{array}$ & $\begin{array}{l}\text { Post- } \\
\text { COVID } \\
\text { Industrial } \\
\text { Related } \\
\text { Variability }\end{array}$ \\
\hline \multirow[t]{4}{*}{$\begin{array}{l}\mathrm{PM}_{2.5} \\
\left(\mu \mathrm{g} / \mathrm{m}^{3}\right)\end{array}$} & High Traffic & 1.4 & -0.2 & $\mathrm{n} / \mathrm{a}$ & $\mathrm{n} / \mathrm{a}$ \\
\hline & $\begin{array}{l}\text { Urban } \\
\text { Residential }\end{array}$ & 1.4 & -0.1 & $\mathrm{n} / \mathrm{a}$ & $\mathrm{n} / \mathrm{a}$ \\
\hline & Suburban & 1.2 & -0.7 & $\mathrm{n} / \mathrm{a}$ & $\mathrm{n} / \mathrm{a}$ \\
\hline & Industrial & 0.4 & -1 & 2.8 & 1.8 \\
\hline \multirow[t]{4}{*}{$\mathrm{CO}(\mathrm{ppb})$} & High Traffic & 180.2 & 77.1 & $\mathrm{n} / \mathrm{a}$ & $\mathrm{n} / \mathrm{a}$ \\
\hline & $\begin{array}{l}\text { Urban } \\
\text { Residential }\end{array}$ & 85.9 & 42.1 & $\mathrm{n} / \mathrm{a}$ & $\mathrm{n} / \mathrm{a}$ \\
\hline & Suburban & 96.2 & 8.8 & $\mathrm{n} / \mathrm{a}$ & $\mathrm{n} / \mathrm{a}$ \\
\hline & Industrial & 103.8 & -22.3 & 272 & 290.2 \\
\hline \multirow[t]{2}{*}{$\mathrm{NO}_{2}(\mathrm{ppb})$} & High Traffic & 7.4 & 4.2 & & \\
\hline & Suburban & 0.2 & 0.1 & & \\
\hline
\end{tabular}

For all site groups, the pre-COVID traffic enhancements of $\mathrm{NO}_{2}$ and $\mathrm{CO}$ generally scale with traffic intensity. $\mathrm{CO}$ enhancements are largest at the High Traffic sites, nearly double the enhancement at the other site groups. Traffic CO enhancements at the Industrial, Urban Residential, and Suburban Residential sites are all similar $(85-104 \mathrm{ppb} \pm 49 \mathrm{ppb})$. The correlation between land use (i.e., traffic volume) and traffic-related $\mathrm{CO}$ enhancements, along with the fact that $\mathrm{CO}$ is non-reactive, supports the use of $\mathrm{CO}$ as a tracer for traffic emissions in these locations. $\mathrm{NO}_{2}$ enhancements at the high traffic ACHD site were $7.4 \mathrm{ppb}( \pm 0.05 \mathrm{ppb})$ compared to $0.2 \mathrm{ppb}$ at the Suburban site.

The traffic enhancements fell post-COVID closures. Enhancements of $\mathrm{CO}$ and $\mathrm{NO}_{2}$ fell at high traffic sites by $57 \%$ and $43 \%$, respectively; this is consistent with the observed $\sim 50 \%$ reduction in commuter traffic. Morning CO enhancements fell to nearly zero in Suburban areas (96.2 to $8.8 \mathrm{ppb}$ ), suggesting a larger fractional reduction in traffic volumes in those areas, consistent with people working and schooling from home. The traffic $\mathrm{CO}$ enhancement became negative in Industrial areas, meaning that concentrations at 7-8am were lower than 2-3am. This is consistent with our observations that although traffic emissions in the mornings have decreased, the overnight industrial emissions have persisted.

$\mathrm{PM}_{2.5}$ enhancements during the morning rush hour in the pre-COVID period were more uniform across site groups. For High Traffic, Urban Residential, and Suburban Residential groups, the morning rush hour $\mathrm{PM}_{2.5}$ enhancement was $1.2-1.4 \mu \mathrm{g} / \mathrm{m}^{3}$, suggesting that traffic is broadly 
distributed. As a result there is a regional increase in morning $\mathrm{PM}_{2.5}$, consistent with the more regional nature of $\mathrm{PM}_{2.5}{ }^{[25-28]}$.

Morning traffic enhancements in $\mathrm{PM}_{2.5}$ were smaller at the Industrial Sites. This may be a consequence of already-enhanced concentrations during the overnight hours at these sites because of nearby industrial emissions. The overnight Industrial $\mathrm{PM}_{2.5}$ enhancement relative to Suburban Residential sites was $2.8 \mu \mathrm{g} / \mathrm{m}^{3}$ in the pre-COVID period. The smaller apparent traffic enhancement at the Industrial sites may also be an artifact of how we determine this enhancement (mean 7-8am minus the mean 2-3am). However, our sensitivity analysis in the SI (Figure S7) shows that the general pattern is robust to the specific sets of hours we use when calculating the enhancements.

In the post-COVID period the morning traffic enhancements for all site groups are within instrument uncertainty of zero, indicating there is no longer a $\mathrm{PM}_{2.5}$ enhancement during the morning rush hour. For all site groups, the morning increase in $\mathrm{PM}_{2.5}$ fell by $0.5-1.5 \mu \mathrm{g} / \mathrm{m}^{3}$, suggesting that the impact of reduced traffic on morning $\mathrm{PM}_{2.5}$ is more regional.

Our analysis suggests that the activity at the industrial sources continued after social distancing was enacted. The industrial $\mathrm{PM}_{2.5}$ enhancement fell from 2.8 (pre-COVID) to $1.8 \mu \mathrm{g} / \mathrm{m}^{3}$ (postCOVID). However, the uncertainty of the $\mathrm{PM}_{2.5}$ measurements are $1.1 \mu \mathrm{g} / \mathrm{m}^{3}$, suggesting that this decrease may not be significant. Similarly, although the corresponding CO industrial enhancement slightly increased in the post-COVID period the increase was once again within the instrument uncertainty suggesting that there was no significant change in industrial $\mathrm{CO}$ enhancement between the pre- and post-COVID time periods as well.

\section{$\underline{\text { Implications }}$}

Our data show a clear decrease in air pollution driven in large part by reductions in vehicle traffic. While the COVID-related shutdowns are unprecedented and do not likely represent the new status quo, they can offer insights into air pollution under future emissions scenarios (e.g., large-scale adoption of electric vehicles). Figure 2 and Table 1 suggest that a $~ 50 \%$ adoption of electric vehicles would essentially eliminate the morning rush hour peak in $\mathrm{PM}_{2.5}, \mathrm{CO}$, and $\mathrm{NO}_{2}$. This could reduce acute exposures, especially in high traffic or near-road environments.

In addition to traffic activity reductions, we also estimated reductions in restaurant activity (by anonymous survey, shown in S8 in the SI) and in electricity related emissions (by calculating the decrease in the metered hourly electricity load supplied by Duquesne Light Company, which provides electricity for $\sim 600,000$ customers in the region). We found that the activity of these sources reduced by $63 \%$ and $8 \%$, respectively. However, determining the impacts of reductions in restaurant emissions and electricity generation on measured pollutant concentrations are more difficult. Neighborhoods with high restaurant impacts have an additional $\sim 1 \mu \mathrm{g} / \mathrm{m}^{3}$ of $\mathrm{PM}_{2.5}$ compared to areas with low restaurant activity ${ }^{[29]}$. Our estimated change in restaurant activity would drop this impact to $\sim 0.4 \mu \mathrm{g} / \mathrm{m}^{3}$. However, the RAMP network does not have sufficient sites in high- and low-restaurant areas to examine this impact in greater detail. Impacts of changes in electricity demand are also difficult to determine directly from our data, as much of 
the $\mathrm{PM}_{2.5}$ from power plants is in the form of secondary sulfate ${ }^{[30]}$. Upwind changes in power plant emissions would therefore be convolved with changes in other upwind emissions and weather patterns. Reductions in electricity generation and restaurant emissions may contribute to the lower overnight background concentrations observed in the post-COVID period.

The most recent policy assessment review for the $\mathrm{PM}_{2.5}$ National Ambient Air Quality Standards (NAAQS) recommended a revision to the annual $\mathrm{PM}_{2.5} \mathrm{NAAQS}$ to as low as $9 \mu \mathrm{g} / \mathrm{m}^{3}$. Such a reduction is estimated to reduce the $\mathrm{PM}_{2.5}$ related mortality rate by $21-27 \%^{[31]}$. The Pittsburgh domain considered here has an annual average $\mathrm{PM}_{2.5}$ concentration of $9.5 \mu \mathrm{g} / \mathrm{m}^{3}$. While evaluating the full impact of vehicle traffic on $\mathrm{PM}_{2.5}$ requires a more thorough assessment of impacts on primary and secondary $\mathrm{PM}_{2.5}$, we can use the observed changes in the morning rush hour peak to make a first-order estimate for the impacts of major changes to vehicle emissions on the annual average $\mathrm{PM}_{2.5}$. We observe that the morning rush hour peak enhancement from 7-8am fell from $1.4 \mu \mathrm{g} / \mathrm{m}^{3}$ to $\sim 0 \mu \mathrm{g} / \mathrm{m}^{3}$. This translates to a reduction of $0.125 \mu \mathrm{g} / \mathrm{m}^{3}$ in the daily average $\mathrm{PM}_{2.5}$ concentration, which would account for a third of the necessary reduction to reach a hypothetical $9 \mu \mathrm{g} / \mathrm{m}^{3}$ standard. Thus, reductions beyond morning rush-hour traffic emissions may be needed to reach $9 \mu \mathrm{g} / \mathrm{m}^{3}$ in urban areas.

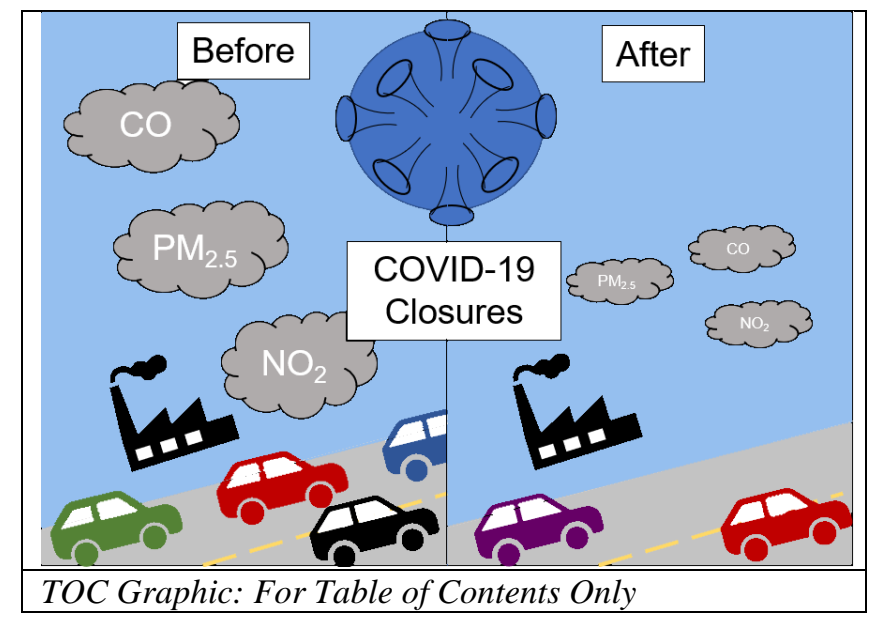

\section{$\underline{\text { Associated Content }}$}

\section{Supporting Information}

Additional details, figures, and tables outlining the timeline for COVID-19 related closures, measurement site groupings and locations, $\mathrm{CO}$ and $\mathrm{PM}_{2.5}$ measurements for the Suburban Residential sites, overall $\mathrm{CO}$ and $\mathrm{PM}_{2.5}$ measurements for the entire domain, $\mathrm{NO}_{2}$ measurements from Allegheny County Health Department, boundary layer height during measurement periods, sensitivity analysis for traffic enhancement calculations, and emissions activity reduction for restaurant cooking and electricity consumption.

\section{Author Information}

Corresponding Author email: apresto@andrew.cmu.edu 
The authors declare no competing financial interest.

\section{Acknowledgements}

This work is part of the Center for Air, Climate and Energy Solution (CACES, www.caces.us). This publication was developed under Assistance Agreement no. RD83587301 awarded by the U.S. Environmental Protection Agency (EPA). This publication has not been reviewed by the EPA. The views expressed in this manuscript do not necessarily represent those of the funding agency. The authors would also like to thank Aliaksei Hauryliuk for maintaining the RAMP sensor network.

\section{$\underline{\text { References }}$}

1. Rich, D. Q. et al. Differences in birth weight associated with the 2008 Beijing olympics air pollution reduction: Results from a natural experiment. Environ. Health Perspect. 123, 880-887 (2015).

2. RANSOM, M. R. \& III, C. A. P. External Health Costs of a Steel Mill. Contemp. Econ. Policy 13, 86-97 (1995).

3. Friedman, M. S., Powell, K. E., Hutwagner, L., Graham, L. R. M. \& Teague, W. G. Impact of changes in transportation and commuting behaviors during the 1996 Summer Olympic Games in Atlanta on air quality and childhood asthma. J. Am. Med. Assoc. 285, 897-905 (2001).

4. Heinrich, J. et al. Improved Air Quality in Reunified Germany and Decreases in Respiratory Symptoms Cyrys, Matthias Wjst, Lucas Neas and H . -Erich Wichmann Published by : Lippincott Williams \& Wilkins Stable URL : http://www.jstor.org/stable/3703762 . Epidemiology 13, 394-401 (2002).

5. Sergent, J., Petras, G. \& Bravo, V. 5 maps show how states differ on protecting Americans against coronavirus. 1-25 (2020). Available at: https://www.usatoday.com/indepth/news/2020/03/24/coronavirus-state-measures-contain-disease-varywidely/2897975001/.

6. Williams, A. Pennsylvania, Delaware Close All Schools Due to Outbreak. 1-8 (2020). Available at: https://www.nbcphiladelphia.com/news/coronavirus/pennsylvania-schoolsclosed-coronavirus/2325564/

7. Parsons, J. Gov . Wolf orders restaurants, bars to close dine-in service in several counties, including Allegheny. 1-8 (2020). Available at: https://www.wtae.com/article/gov-wolforders-restaurant-bars-to-close-dine-in-several-counties-including-allegheny/31649498

8. Wolf, T. All non-life-sustaining businesses in Pennsylvania to close physical locations as of 8 PM today to slow spread of COVID-19. 1-2 (2020). Available at: https://www.governor.pa.gov/newsroom/all-non-life-sustaining-businesses-inpennsylvania-to-close-physical-locations-as-of-8-pm-today-to-slow-spread-of-covid-19/

9. Bosco, T. 3 COVID-19 cases confirmed in Ohio, DeWine declaring state of emergency. 1-7 (2020). Available at: https://abc6onyourside.com/news/local/gov-dewine-ohio-has-3confirmed-covid-19-coronavirus-cases 
10. Kiser, J. Coronavirus in Ohio : Governor orders schools to take extended spring breaks starting Monday All segment download attempts within FAILED _ SEQ _ LIMIT failed Coronavirus in Ohio resources : 1-11 (2020). Available at: https://www.nbc4i.com/news/local-news/coronavirus-in-ohio-governor-orders-schools-totake-extended-spring-breaks-starting-monday/

11. Zimmerman, N. et al. A machine learning calibration model using random forests to improve sensor performance for lower-cost air quality monitoring. Atmospheric Measurement Techniques. 291-313 (2018).

12. Malings, C. et al. Fine particle mass monitoring with low-cost sensors : Corrections and long-term performance evaluation term performance evaluation. Aerosol Sci. Technol. 0, $1-15$ (2019).

13. Malings, C. et al. Development of a general calibration model and long-term performance evaluation of low-cost sensors for air pollutant gas monitoring. Atmospheric Measurement Techniques. 903-920 (2019).

14. Tanzer, R., Malings, C., Hauryliuk, A. \& Subramanian, R. Demonstration of a Low-Cost Multi-Pollutant Network to Quantify Intra-Urban Spatial Variations in Air Pollutant Source Impacts and to Evaluate Environmental Justice. International Journal of Environmental Research and Public Health (2019).

15. Zimmerman, N. et al. Improving correlations between land use and air pollutant concentrations using wavelet analysis: Insights from a low-cost sensor network. Aerosol Air Qual. Res. 20, 314-328 (2020).

16. Subramanian, R. et al. Air Quality in Puerto Rico in the Aftermath of Hurricane Maria: A Case Study on the Use of Lower Cost Air Quality Monitors. ACS Earth and Space Chemistry 1179-1186 (2018). doi:10.1021/acsearthspacechem.8b00079

17. Castell, N. et al. Can commercial low-cost sensor platforms contribute to air quality monitoring and exposure estimates? Environ. Int. 99, (2017).

18. Cross, E. S. et al. Use of electrochemical sensors for measurement of air pollution: Correcting interference response and validating measurements. Atmos. Meas. Tech. 10, 3575-3588 (2017).

19. Eilenberg, R. et al. Using a Network of Lower-Cost Monitors to Identify the Influence of Modifiable Factors Driving Spatial Patterns in Fine Particulate Matter Concentrations in an Urban Environment . Submitted 2020

20. Hagan, D. H. et al. Calibration and assessment of electrochemical air quality sensors by co-location with regulatory-grade instruments. Atmospheric Measurement Techniques 315-328 (2018).

21. Snyder, E. G. et al. The changing paradigm of air pollution monitoring. Environ. Sci. Technol. 47, 11369-77 (2013).

22. Google LLC. Pennsylvania April 11, 2020 Mobility changes. (2020). Available at: https://www.google.com/covid19/mobility/ 
23. Weitkamp, E. A. et al. Fine particle emission profile for a large coke production facility based on highly time-resolved fence line measurements. Atmos. Environ. 39, 6719-6733 (2005).

24. Presto, A. a, Dallmann, T. R., Gu, P. \& Rao, U. BTEX exposures in an area impacted by industrial and mobile sources: Source attribution and impact of averaging time. J. Air Waste Manag. Assoc. 66, 387-401 (2016).

25. Robinson, A. L. et al. Rethinking Organic Aerosols : Semivolatile Emissions and. Science. 315, 1259-1263 (2008).

26. Jimenez, J. L. et al. Evolution of Organic Aerosols in the Atmosphere. Science. 326 15251530 (2009).

27. Li, H. Z., Dallmann, T. R., Gu, P. \& Presto, A. A. Application of mobile sampling to investigate spatial variation in fine particle composition. Atmospheric Environment 142, 71-82 (2016).

28. Tang, W. et al. Spatial variations of PM2.5 during the Pittsburgh air quality study. Aerosol Sci. Technol. 38, 80-90 (2004).

29. Gu, P. et al. Intracity Variability of Particulate Matter Exposure Is Driven by Carbonaceous Sources and Correlated with Land-Use Variables. Environ. Sci. Technol. 52, 11545-11554 (2018).

30. Morris, R. E., Jung, J., Koo, B. \& Maranche, J. Application of an integrated plume to regional photochemical model for the allegheny county liberty-clairton PM2.5 attainment demonstration modeling. Air Waste Manag. Assoc. - Guidel. Air Qual. Model. 2013 Path Forw. 2, 874-901 (2013).

31. US EPA. Policy Assessment for the Review of the Particulate Matter National Ambient Air Quality Standards. U.S. Environmental Protection Agency, Office of Air Quality Planning and Standards, (2019). Available at: https://www.epa.gov/sites/production/files/201909/documents/draft_policy_assessment_for_pm_naaqs_09-05-2019.pdf 